\title{
EFFECT OF FREEZE-DRYING AND AIR-DRYING ON THE CONTENT OF CAROTENOIDS AND ANTHOCYANINS IN STORED PURPLE CARROT
}

\author{
Ryszard Macura, Magdalena Michalczyk ${ }^{\bowtie}$, Grzegorz Fiutak, Ireneusz Maciejaszek
}

Department of Refrigeration and Food Concentrates, University of Agriculture in Krakow Balicka 122, 30-149 Krakow, Poland

\begin{abstract}
Background. In stored freeze-dried orange carrots, carotenoids are not stable compounds. The aim of the work was to evaluate the stability of carotenoids in products obtained from polyphenol-rich purple carrots which additionally contain anthocyanins.

Material and methods. This study compares the effect of air-drying and freeze-drying as well as 6-month storage on the content of carotenoids, anthocyanins and total phenolics in dried products obtained from purple carrot.

Results. The phenolic compounds found in the greatest amounts in carrot were ferulic acid cyanidin 3-xylosylglucosylgalactoside, p-coumaric acid cyanidin 3-xylosylglucosylgalactoside, chlorogenic acid, and caffeic-quinic acid. Freeze-drying did not significantly reduce levels of carotenoids and anthocyanin content, while air-drying led to substantial losses of carotenoids, anthocyanins and polyphenols. 6-month storage of freeze-dried products caused losses of carotenoids, anthocyanins and total polyphenols of $42 \%, 33 \%$ and $53 \%$ respectively when compared with the raw material. In air-dried products, the losses were $66 \%, 33 \%$ and $36 \%$, respectively.

Conclusion. The results indicate that the combined effect of freeze-drying and 6-month storage was reduced losses of carotenoids compared to traditionally dried products.
\end{abstract}

Keywords: purple carrot, anthocyanins, carotenoids, freeze-drying, air-drying, storage

\section{INTRODUCTION}

Carrots (Daucus carota L.) are an important source of carotenoids in the human diet (Desobry et al., 1998). According to the literature, total carotenoids in carrots range from 0 to $480 \mathrm{mg} \cdot \mathrm{kg}^{-1}$ depending on the root colour (white, yellow, orange, or purple) and the cultivar (Baranski et al., 2012; Mech-Nowak et al., 2012). Due to their highly unsaturated structure, carotenoids are susceptible to oxidation. Their degradation is affected by the presence of oxygen, exposure to light, high temperatures, fragmentation of the raw material and the activity of oxidative enzymes (van den Berg et al., 2000). The extent of losses depends on both the method of processing and the storage conditions (Alasalvar et al., 2005; Desobry et al., 1998; Pinheiro Sant'Ana et al., 1998; Tang and Chen, 2000; Yen et al., 2008). Purple carrots also contain anthocyanins in

This research was financed by the Ministry of Science and Higher Education of the Republic of Poland.

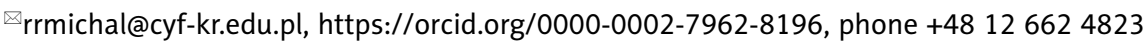


the range of $15-1687 \mathrm{mg} \cdot \mathrm{kg}^{-1}$ (Algarra et al., 2014; Assous et al., 2014; Leja et al., 2013; Li et al., 2012; Montilla et al., 2011). The findings of Arscott et al. (2010) suggest that the presence of anthocyanins does not reduce the assimilation of carrot-derived carotenoids. Akhtar et al. (2017) also pay attention to a wide array of flavonoids occurring in black carrots, which may play a beneficial role in reducing degenerative diseases. However, according to Charron et al. (2009), the bioavailability of anthocyanins in purple carrots is reduced since they occur mainly in acylated form. In turn, Karkute et al. (2018) suggest that anthocyanins derived from black carrots may have a beneficial effect on the control of diabetes. Kumar et al. (2018) observed that black carrot anthocyanins, when added to plum, pomegranate, strawberry and jamun juices, acted as a color enhancer and thermal stabiliser, which the authors explain by co-pigmentation.

The stability of anthocyanins is also significantly affected by such factors as changes in $\mathrm{pH}$, increased temperature, enzyme activity, vitamin $\mathrm{C}$ and the presence of oxygen (De Pascual-Teresa and Sanchez-Ballesta, 2008).

Drying is one of the methods used to process carrots and can take the form of either air-drying or freeze-drying. Generally, the latter results in better quality retention than the former. Air-drying causes not only substantial shrinkage of the material and large losses of flavour, but also a reduction in heat-labile components, depending on the drying temperature. Freeze-drying allows much better retention of shape and colour, rehydration capacity, and retention of heat-labile components. Although the freeze-drying process itself does not significantly reduce carotenoid content in carrots, considerable losses of these compounds occur during the storage of freeze-dried products (Desobry et al., 1998; Macura, 2009); 2- and 4-month storage can lead to losses of up to $60 \%$ and $90 \%$ respectively, which may cause problems in the production of concentrates obtained from freezedried products (Macura, 2009).

Due to their antioxidant properties, the anthocyanins and high levels of polyphenol compounds in purple carrots may affect the stability of carotenoids in stored freeze-dried products. Therefore, the aim of this study was to evaluate the effect of freeze-drying and air-drying and subsequent storage on the stability of carotenoids and anthocyanins in purple carrots.

\section{MATERIAL AND METHODS}

Carrot roots (Daucus carota ssp. sativus var. atrorubens Alef.) were supplied by a local producer. The variety, intended both for the fresh market and for processing, was characterized by a dark purple color.

The raw material was washed, boiled at $100^{\circ} \mathrm{C}$ for $15 \mathrm{~min}$ and then peeled, sliced $(5 \mathrm{~mm})$ and dried. The purpose of boiling was to stabilise the anthocyanins in the raw material. The conventionally dried product was air-dried at $45^{\circ} \mathrm{C}$ for 24 hours. The freeze-drying process was initiated by freezing the material to $-23^{\circ} \mathrm{C}$, followed by freeze-drying in a Labor MIM OE-950 freeze-dryer (Budapest, Hungary) at a shelf temperature of $35^{\circ} \mathrm{C}$ for $24 \mathrm{~h}$. After drying, the carrots were packed into glass jars and stored for 6 months at room temperature without exposure to light. Analyses were performed on the fresh raw material, and on dried products 24 hours after drying and every month throughout the period of storage.

\section{Extraction of anthocyanins and total phenolics}

Extracts for determining total phenolic content and total anthocyanin content were obtained by threefold extraction using a mixture of ethanol and water $(60: 40 \mathrm{v} / \mathrm{v})$ containing $0.01 \% \mathrm{HCl}$. Extracts derived from dried products were obtained after rehydration to moisture levels similar to those in fresh carrots.

\section{Total phenolic content}

Total phenolic content was determined according to Singleton and Rossi (1965) using the Folin-Ciocalteau reagent. Measurements were performed at $750 \mathrm{~nm}$ using a Cecil CE 9500 spectrophotometer (Cecil Instruments, Cambridge, England). Results were expressed as gallic acid equivalents $\left(\mathrm{mg} \cdot \mathrm{kg}^{-1}\right.$ of dry matter).

\section{Determination of total anthocyanins}

Total anthocyanin content was determined spectrophotometrically using the differential $\mathrm{pH}$ method (Lee et al., 2005) modified by Kidoń and Czapski (2008). The modification was introduced due to the high proportion of acylated anthocyanins in the raw material. The extracts were diluted with $\mathrm{pH} 1(\mathrm{KCl}$ and $\mathrm{HCl}$ buffer) and pH 6 (McIlvaine phosphate buffer). Absorbance measurements were taken at wavelengths of 
520 and $700 \mathrm{~nm}$. Results were expressed as cyanidin-3-glucoside ( $\mathrm{mg} \cdot \mathrm{kg}^{-1}$ of dry matter).

\section{Identification of phenolic compounds}

The profile analysis of phenolic components was performed using an ACQUITY Ultra Performance LC system (UPLC) with binary solvent manager, UPLC BEH C18 column, DAD detector (Waters Corporation, Milford, MA, USA) and mass detector G2 Q/TOF micro mass spectrometer (Waters, Manchester, U.K.). The unprocessed raw material was frozen $\left(-40^{\circ} \mathrm{C}\right)$ and stored in this form until the moment of analysis. After comminuting, the samples were extracted with $40 \%$ methanol in water acidified with $4.5 \%$ formic acid. Extraction was carried out twice. $10 \mu \mathrm{L}$ of the resulting extract was then injected into the column. Conditions of the separation of compounds were set and maintained according to Oszmiański et al. (2013) and results were obtained by comparing the results of the DAD measuring spectra with standards.

\section{Carotenoids}

The content of carotenoids was determined by high performance liquid chromatography (HPLC) using a LaChrom chromatograph (Merck-Hitachi) equipped with a L-7450 diode array detector, a L-7100 gradient pump, a L-7250 autosampler and a D7000 interface. Separations were carried out on a LiChrosphere 100 RP-18 column $(5 \mu \mathrm{m} ; 250 \times 4 \mathrm{~mm}$; Merck Darmstadt Germany). The column temperature was maintained at $30^{\circ} \mathrm{C}$. Mobile phases consisted of methanol/acetonitryle $(9: 1 \mathrm{v} / \mathrm{v})$, acetone and $1 \mathrm{M}$ ammonium acetate. Extraction of samples and separations at a flow rate of $1 \mathrm{~mL} / \mathrm{min}$ in gradient manner were performed according to Fiutak et al. (2019). Detection of carotenoids was conducted at $350-750 \mathrm{~nm}$. The content of carotenoids was evaluated on the basis of standard curves.

\section{Statistical analysis}

Identification of phenolic compounds was done in duplicates, while other analyses were performed in triplicate. Results were expressed as mean $\pm \mathrm{SD}$. The significance of difference between means was determined by one-way ANOVA and Tukey's test at $p<0.05$, using CSS Statistica software (StatSoft, Inc., USA).

\section{RESULTS AND DISCUSSION}

\section{Phenolic compounds}

The components that attract attention are anthocyanins, which give the purple carrots their distinctive colour. All major anthocyanins contain cyanidin as an aglycon (Schwarz et al., 2004). Anthocyanin content in the raw material measured by the $\mathrm{pH}$ differential method was very high, at $1399 \mathrm{mg} \cdot \mathrm{kg}^{-1}$ of fresh weight $\left(9027 \mathrm{mg} \cdot \mathrm{kg}^{-1}\right.$ d.m.). While freeze-drying did not affect anthocyanin content, air-drying led to significant losses (Fig. 1). Up to the third month of storage, anthocyanin content in freeze-dried carrots was considerably higher than in the air-dried product; thereafter, levels in both products were very similar. After storage, the retention was about $67 \%$ of initial values. Table 1 shows the separation of phenolic compounds in the raw material, the freeze-dried product, and air-dried product. In each case, total anthocyanins were significantly greater when determined by HPLC than when using the $\mathrm{pH}$ differential method. A similar phenomenon was reported by Lee et al. (2008). The authors cited observed a high correlation $(R \geq 0.925)$ between anthocyanin content in various raw materials determined by the HPLC method and the $\mathrm{pH}$ differential method, pointing out that the latter was a simple, rapid, and good alternative.

In the present work, losses of both anthocyanins and total phenolic compounds were considerably higher in the air-dried product than in freeze-dried carrots (Table 1; Fig. 1, 2). Individual anthocyanins are listed in Table 1, showing ferulic acid cyanidin 3-xylosylglucosylgalactoside as the most abundant, which is consistent with the findings of Algarra et al. (2014) for the black carrot cultivar, Antonina. The authors found that cyanidin 3-xylosylglucosylgalactoside, cyanidin 3 -xylosylgalactoside and sinapic, ferulic and coumaric acids derived of cyanidin 3-xylosylglucosylgalactoside are the main anthocyanins in the cultivars Antonina and Purple Haze. However, there were differences in the proportions of anthocyanins between the two cultivars. Furthermore, anthocyanins comprised $25 \%$ of total phenolic content in Purple Haze and 50\% in Antonina; the latter value is similar to the result obtained in the present work. Smeriglio et al. (2018) also reported that, of the substances determined by the authors in the polyphenolic profile of crude black carrot 
Macura, R., Michalczyk, M., Fiutak, G., Maciejaszek, I. (2019). Effect of freeze-drying and air-drying on the content of carotenoids and anthocyanins in stored purple carrot. Acta Sci. Pol. Technol. Aliment., 18(2), 135-142. http://dx.doi.org/10.17306/ J.AFS.2019.0637

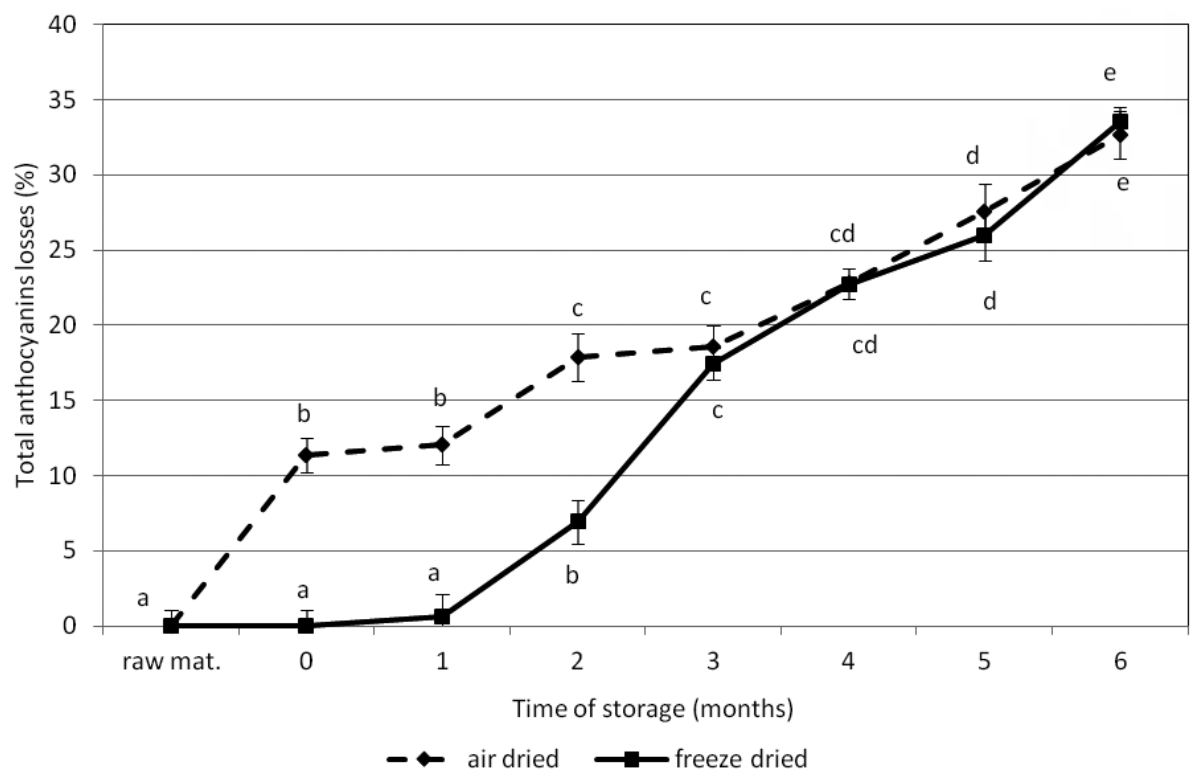

Fig. 1. Effect of drying and subsequent 6-month storage on anthocyanin content in air-dried and freeze-dried purple carrot: raw mat. - unprocessed raw material; time 0 - material $24 \mathrm{~h}$ after processing. Mean values relating to the same series, denoted with different letters are significantly different $(p<0.05)$

Table 1. Phenolic compounds in fresh raw material and in air- and freeze-dried product $24 \mathrm{~h}$ after processing, $\mathrm{mg} \cdot \mathrm{kg}^{-1} \mathrm{dry}$ matter

\begin{tabular}{lccc}
\hline \multicolumn{1}{c}{ Constituents } & Fresh raw material & Air-dried product & Freeze-dried product \\
\hline Cyanidin 3-xylosylglucosyl-galactoside & $2779 \pm 44.2$ & $1996 \pm 8.8$ & $2843 \pm 17.5$ \\
Cyanidin 3-xylosylgalactoside & $1162 \pm 18.3$ & $430 \pm 0.7$ & $935 \pm 2.8$ \\
Sinapic acid cyanidin 3-xylosy-glucosylgalactoside & $1402 \pm 46.5$ & $1043 \pm 7.4$ & $1123 \pm 5.4$ \\
Ferulic acid cyanidin 3-xylosyl-glucosylgalactoside & $23656 \pm 69.8$ & $13851 \pm 70.7$ & $19578 \pm 1.5$ \\
p-Coumaric acid cyanidin & $4877 \pm 63.0$ & $3751 \pm 22.6$ & $5306 \pm 4.2$ \\
3-xylosyl-glucosylgalactoside & 33876 & 21071 & 29785 \\
Total anthocyanins & $1849 \pm 27.8$ & $1621 \pm 0.7$ & $1916 \pm 1.2$ \\
Neochlorogenic acid & $16294 \pm 52.4$ & $12838 \pm 71.4$ & $14723 \pm 50.2$ \\
Chlorogenic acid & $1470 \pm 37.0$ & $1111 \pm 10.8$ & $1393 \pm 5.9$ \\
Cryptochlorogenic acid & $3672 \pm 6.8$ & $2238 \pm 4.0$ & $4034 \pm 2.8$ \\
Caffeic-quinic acid & 56161 & 38879 & 51851 \\
Total & & & \\
\hline
\end{tabular}


Macura, R., Michalczyk, M., Fiutak, G., Maciejaszek, I. (2019). Effect of freeze-drying and air-drying on the content of carotenoids and anthocyanins in stored purple carrot. Acta Sci. Pol. Technol. Aliment., 18(2), 135-142. http://dx.doi.org/10.17306/ J.AFS.2019.0637

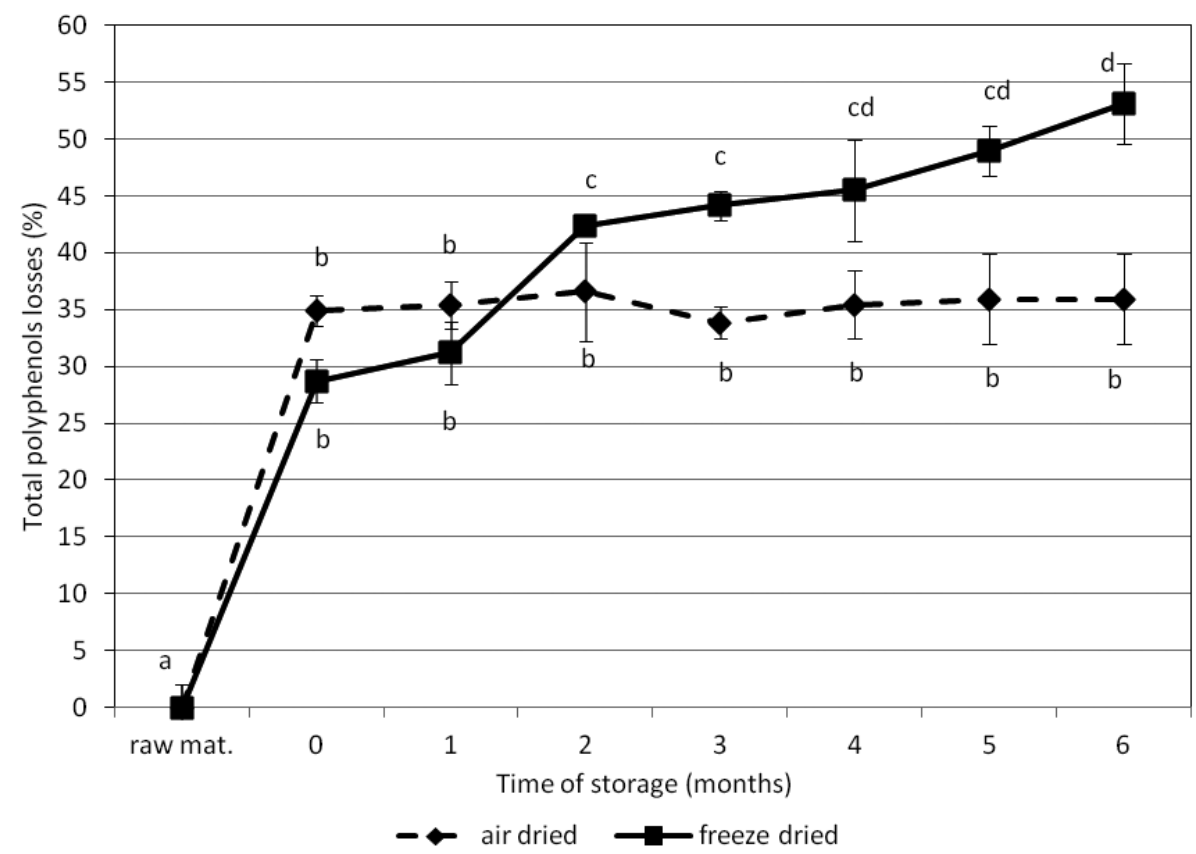

Fig. 2. Effect of drying and subsequent 6-month storage on total polyphenol content in air-dried and freeze-dried purple carrot: raw mat. - unprocessed raw material; time 0 - material $24 \mathrm{~h}$ after processing. Mean values relating to the same series, denoted with different letters are significantly different $(p<0.05)$

extract, cyanidin 3-xylosyl(feruloyl-glucosyl)galactoside was found in the highest amounts, followed by chlorogenic acid.

Total phenolic content in the fresh material was $39765 \mathrm{mg} \cdot \mathrm{kg}^{-1}$ d.m. and was similar to that reported by Algarra et al. (2014). Changes of total phenolic content in the stored material are given in Figure 2. Freeze-drying resulted in reduced losses of these components than conventional air-drying, and this difference in favour of the freeze-dried product persisted through the first month of storage. However, as the storage period progressed, the retention of total phenolic compounds became distinctly higher in the air-dried product. Several studies have found that freeze-drying results in superior retention of phenolic compounds than air-drying in a variety of dried and stored fruits and vegetables (Korus, 2011; Michalczyk et al., 2009; Tseng and Zhao, 2012). However, Tseng and Zhao (2012) reported that losses during storage were smallest in air-dried wine grape pomace and that the highest final content of phenolic compounds in freeze-dried products was mainly due to the small losses occurring during the freeze-drying process.

According to Schwarz et al. (2004) and the literature cited by those authors, chlorogenic acid is the most abundant non-anthocyanin phenolic compound in purple carrots. This was also found to be the case in the present work, with caffeic-quinic acid being the next most abundant (Table 1).

\section{Carotenoids}

The content of carotenoids in the fresh raw material was $370.2 \mathrm{mg} \cdot \mathrm{kg}^{-1}$ d.m., which is not particularly high when compared with many varieties of orange carrot. Nevertheless, some studies of purple carrot revealed high carotenoid concentrations, for example, 200-230 $\mathrm{mg} \cdot \mathrm{kg}^{-1}$ fresh weight in the cultivar, Beta Sweet (Lee et al., 2011). What stands out in the present work, however, is the high proportion of lutein in total carotenoids (Fig. 3). The similar content of carotenoids and 
Macura, R., Michalczyk, M., Fiutak, G., Maciejaszek, I. (2019). Effect of freeze-drying and air-drying on the content of carotenoids and anthocyanins in stored purple carrot. Acta Sci. Pol. Technol. Aliment., 18(2), 135-142. http://dx.doi.org/10.17306/ J.AFS.2019.0637

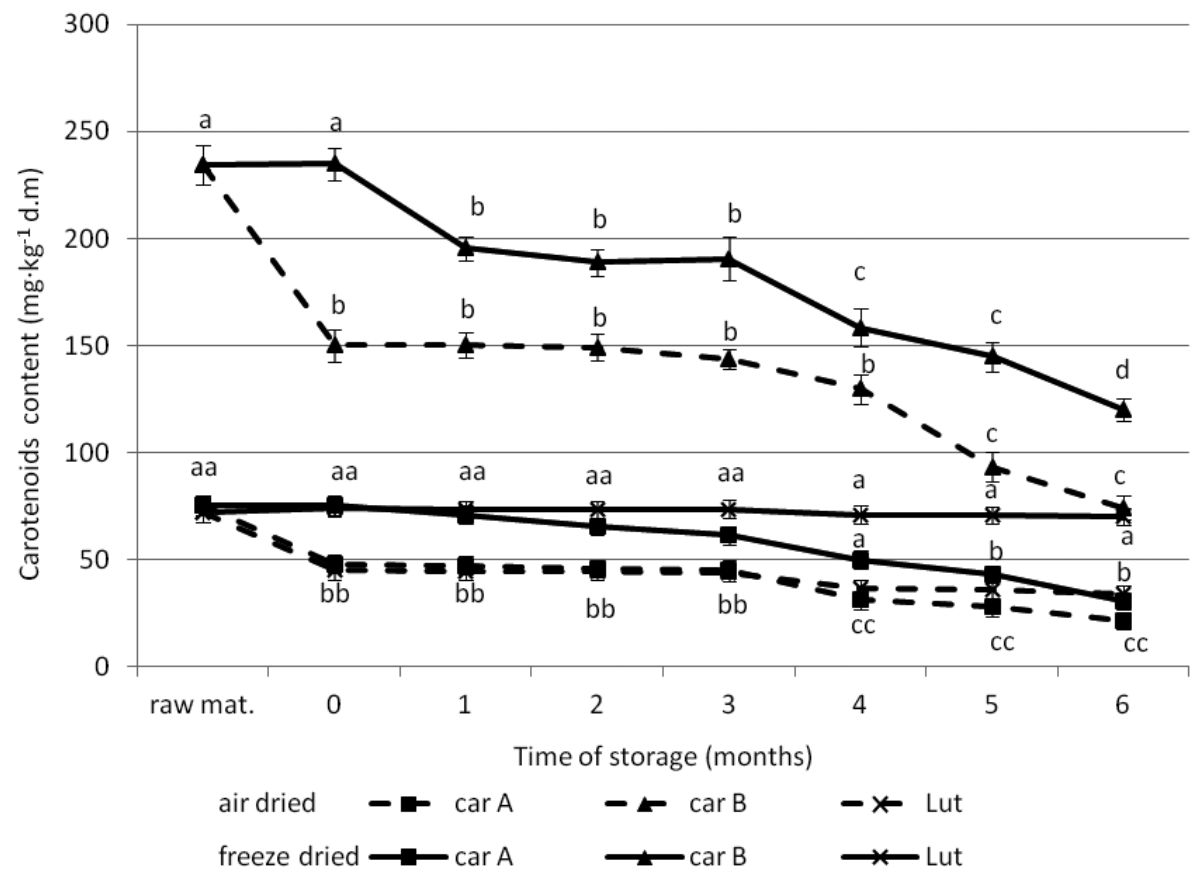

Fig. 3. Effect of drying and subsequent 6-month storage on carotenoid content in air-dried and freeze-dried purple carrot: car A - alpha-carotene, car B - beta-carotene, Lut - lutein, raw mat. - unprocessed raw material; time 0 - material $24 \mathrm{~h}$ after processing. Mean values relating to the same series, denoted with different letters are significantly different $(p<0.05)$

high proportion of lutein in Deep Purple cultivar was reported by Metzger and Barnes (2009). Traditional air-drying reduced carotenoid content by $36.2 \%$, while freeze-drying actually resulted in a small increase $(0.7 \%)$, presumably due to improved extraction conditions. During the first 3 months of storage, only slight losses were recorded, particularly in the freeze-dried product; between the 3rd and 6th months of storage, carotenoid degradation accelerated. After 6 months of storage, the carotenoid content in freeze- and airdried products was $57.8 \%$ and $34.2 \%$ respectively of that found in the raw material. Negi and Roy (2001) found that b-carotene content in blanched, air-dried carrots stored for 6 months fell from an initial value of $290 \mathrm{mg} \cdot \mathrm{kg}^{-1}$ to $160-200 \mathrm{mg} \cdot \mathrm{kg}^{-1}$ dry weight, depending on storage temperature and type of packaging. Carotenoids in freeze-dried orange carrots are highly unstable; Macura (2009) observed losses of up to $90 \%$ after 4 months of storage. According to Phanindra Kumar et al. (2001), the higher losses found in freeze-dried carrots and pumpkins after 6 months of storage compared with those dried in hot air, are due to their porous texture allowing access to oxygen together with their low water activity. The work cited reported carotenoid loss of about $70 \%$ in carrots dried in hot air and stored for 6 months at $25^{\circ} \mathrm{C}$. A similar result was also recorded for traditionally dried purple carrots (Fig. 3). Carotenoids in the freeze-dried products were much more stable; losses of about $40 \%$ after 6-months of storage may be regarded as relatively low. Carotenoid loss in air-dried products occurred mainly during the drying process, with subsequent losses during storage being relatively small. In both types of products, the stability of individual carotenoids was different. In freeze-dried products, lutein was found to be stable, while losses of $\alpha$-carotene and $\beta$-carotene were large. In conventionally dried products which were stored for 6 months, losses in all examined carotenoids exceeded $50 \%$ compared to the raw carrot; the smallest were observed in lutein content. 
Macura, R., Michalczyk, M., Fiutak, G., Maciejaszek, I. (2019). Effect of freeze-drying and air-drying on the content of carotenoids and anthocyanins in stored purple carrot. Acta Sci. Pol. Technol. Aliment., 18(2), 135-142. http://dx.doi.org/10.17306/ J.AFS.2019.0637

\section{CONCLUSIONS}

As was expected and in contrast to air-drying, the process of freeze-drying resulted in fairly small changes in the content of carotenoids and anthocyanins. However, losses of total polyphenols were significant and similar in both products. After the $3^{\text {rd }}$ month of storage, anthocyanin content was roughly equal in both products, whereas the content of total polyphenols was lower in the freeze-dried product. The greatest advantage of freeze-drying over air-drying was in carotenoid content, which resulted mainly from smaller losses in the drying process itself. Cumulative loss of carotenoids during freeze-drying and 6-months of storage was smaller than in air-drying and subsequent storage. The 6-month storage period led to similar percentage losses of carotenoids in freeze-dried and in air-dried products.

\section{REFERENCES}

Akhtar, S., Rauf, A., Imran, M., Qamar, M., Riaz, M., Mubarak, M. S. (2017). Black carrot (Daucus carota L.), dietary and health promoting perspectives of its polyphenols: A review. Trends Food Sci. Technol., 66, 36-47. https://doi.org/10.1016/j.tifs.2017.05.004

Alasalvar, C., Al-Farsi, M., Quantick, P. C., Shahidi, F., Wiktorowicz, R. (2005). Effect of chill storage and modified atmosphere packaging (MAP) on antioxidant activity, anthocyanins, carotenoids, phenolics and sensory quality of ready-to-eat shredded orange and purple carrots. Food Chem., 89, 69-76. https://doi.org/10.1016/j. foodchem.2004.02.013

Algarra, M., Fernandes, A., Mateus, N., de Freitas, V., Esteves da Silva, J. C. G., Casado, J. (2014). Anthocyanin profile and antioxidant capacity of black carrots (Daucus carota L. ssp. sativus var. atrorubens Alef.) from Cuevas Bajas, Spain. J. Food Compost. Anal., 33, 71-76. https:// doi.org/10.1016/j.jfca.2013.11.005

Arscott, S. A., Simon, P. W., Tanumihardjo, S. A. (2010). Anthocyanins in purple-orange carrots (Daucus carota L.) do not influence the bioavailability of $\beta$-carotene in young women. J. Agric. Food Chem., 58, 2877-2881. https://doi.org/10.1021/jf9041326

Assous, M. T. M., Abdel-Hady, M. M., Medany, G. M. (2014). Evaluation of red pigment extracted from purple carrots and its utilization as antioxidant and natural food colorants. Ann. Agric. Sci., 59(1), 1-7. https://doi. org/10.1016/j.aoas.2014.06.001

Baranski, R., Allender, Ch., Klimek-Chodacka, M. (2012). Towards better tasting and more nutritious carrots:
Carotenoid and sugar content variation in carrot genetic resources. Food Res. Int., 47, 182-187. https://doi.org/ 10.1016/j.foodres.2011.05.006

Charron, C. S., Kurilich, A. C., Clevidence, B. A., Simon, P. W., Harrison, D. J., Britz S. J., ..., Novotny, J. A. (2009). Bioavailability of anthocyanins from purple carrot juice: Effects of acylation and plant matrix. J. Agric. Food Chem., 57, 1226-1230. https://doi.org/10.1021/ jf802988s

Desobry, S. A., Netto, F. M., Labuza, T. P. (1998). Preservation of $\beta$-carotene from carrots. Crit. Rev. Food Sci. Nutr., 38(5), 381-396. https://doi.org/10.1080/104086 99891274255

De Pascual-Teresa, S., Sanchez-Ballesta, M. T. (2008). Anthocyanins: from plant to health. Phytochem. Rev., 7, 281-299. https://doi.org/10.1007/s11101-007-9074-0

Fiutak, G., Michalczyk, M., Filipczak-Fiutak, M., Fiedor, L., Surówka, K. (2019). The impact of LED lighting on the yield, morphological structure and some bioactive components in alfalfa (Medicago sativa L.) sprouts. Food Chem., 285, 53-58. https://doi.org/10.1016/j. foodchem.2019.01.086

Karkute, S. G., Koley, T. K., Yengkhom, B. K., Tripathi, A., Srivastava, S., Maurya, A., Singh, B. (2018). Antidiabetic phenolic compounds of black carrot (Daucus carota subspecies sativus var. atrorubens Alef.) inhibit enzymes of glucose metabolism: An in silico and in vitro validation. Med. Chem., 14(6), 641-649. https://doi.org /10.2174/1573406414666180301092819

Kidoń, M., Czapski, J. (2008). Spektrofotometryczna różnicowa metoda oznaczania acylowanych antocyjanów na przykładzie barwników marchwi purpurowej [Spectrophotometrical differential method of the quantitative measurement of acylated anthocyanins on the example of purple carrot pigment]. Apar. Bad. Dydakt., 13(4), 82-86 [in Polish].

Korus, A. (2011). Effect of preliminary processing, method of drying and storage temperature on the level of antioxidants in kale (Brassica oleracea L. var. acephala) leaves. LWT-Food Sci. Technol.,44, 1711-1716.https://doi.org/ 10.1016/j.lwt.2011.03.014

Kumar, M., Dahuja, A., Sachdev, A., Kaur, C., Varghese, E., Saha, S., Sairam, K. V. S. S. (2018). Black carrot (Daucus carota ssp.) and black soybean (Glycine max (L.) Merr.) anthocyanin extract: A remedy to enhance stability and functionality of fruit juices by copigmentation. Waste Biomass. Valor. [article in press]. https://doi. org/10.1007/s12649-018-0450-3

Lee, J., Durst, R. W., Wrolstad, R. E. (2005). Determination of total monomeric anthocyanin pigment content of fruit juices, beverages, natural colorants, and wines by the $\mathrm{pH}$ 
Macura, R., Michalczyk, M., Fiutak, G., Maciejaszek, I. (2019). Effect of freeze-drying and air-drying on the content of carotenoids and anthocyanins in stored purple carrot. Acta Sci. Pol. Technol. Aliment., 18(2), 135-142. http://dx.doi.org/10.17306/ J.AFS.2019.0637

differential method: collaborative study. J. AOAC Int., 88(5), 1269-1278.

Lee, J., Rennaker, C., Wrolstad, R. E. (2008). Correlation of two anthocyanin quantification methods: HPLC and spectrophotometric methods. Food Chem., 110, 782786. https://doi.org/10.1016/j.foodchem.2008.03.010

Lee, E. J., Yoo, K. S., Patil, B. S. (2011). Total carotenoid, anthocyanin, and sugar contents in sliced or whole purple (cv. BetaSweet) and orange carrots during 4-week cold storage. Hortic. Environ. Biotec., 52(4), 402-407. https://doi.org/10.1007/s13580-011-0227-0

Leja, M., Kamińska, I., Kramer, M., Maksylewicz-Kaul, A., Kammerer, D., Carle, R., Baranski, R. (2013). The content of phenolic compounds and radical scavenging activity varies with carrot origin and root color. Plant Foods Hum. Nutr., 68, 163-170. https://doi.org/10.1007/ s11130-013-0351-3

Li, H., Deng, Z., Zhu, H., Hu, C., Liu, R., Young, J. C., Tsao, R. (2012). Highly pigmented vegetables: Anthocyanin compositions and their role in antioxidant activities. Food Res. Int., 46, 250-259. https://doi.org/10.1016/j. foodres.2011.12.014

Macura, R. (2009). Badania nad poprawą trwałości karotenoidów w liofilizowanej marchwi [Studies on improvement in carotenoid stability in freezed-dried carrot]. Zesz. Nauk. UR Krak., 453, Rozpr. 330 [in Polish].

Mech-Nowak, A., Świderski, A., Kruczek, M., Łuczak, I., Kostecka-Gugała, A. (2012). Content of carotenoids in roots of seventeen cultivars of Daucus carota L. Acta Biochim. Pol., 59(1), 139-141. http://psjd.icm.edu.pl/ psjd/element/bwmeta1.element.bwnjournal-article-abpv59p139kz

Metzger, B. T., Barnes, D. M. (2009). Polyacetylene diversity and bioactivity in orange market and locally grown colored carrots (Daucus carota L.). J. Agric. Food Chem., 57, 11134-11139. https://doi.org/10.1021/jf9025663

Michalczyk, M., Macura, R., Matuszak, I. (2009). The effect of air-drying, freeze-drying and storage on the quality and antioxidant activity of some selected berries. J. Food Process. Preserv., 33(1), 11-21. https://doi. org/10.1111/j.1745-4549.2008.00232.x

Montilla, E. C., Arzaba, M. R., Hillebrand, S., Winterhalter, P. (2011). Anthocyanin composition of black carrot (Daucus carota ssp. sativus var. atrorubens Alef.) cultivars Antonina, Beta Sweet, Deep Purple, and Purple Haze. J. Agric. Food. Chem., 59, 3385-3390. https://doi. org/10.1021/jf104724k

Negi, P. S., Roy, S. K. (2001). The effect of blanching on quality attributes of dehydrated carrots during long-term storage. Eur. Food Res. Technol., 212(4), 445-448.
Oszmiański, J., Kolniak-Ostek, J., Wojdyło, A. (2013). Application of ultra performance liquid chromatographyphotodiode detector-quadrupole/time of flight-mass spectrometry (UPLC-PDA-Q/TOF-MS) method for the characterization of phenolic compounds of Lepidium sativum L. sprouts. Eur. Food Res. Technol., 236, 699706. https://doi.org/10.1007/s00217-013-1925-x

Phanindra Kumar, H. S., Radhakrishna, K. K., Nagaraju, P. K., Vijaya Rao, D. (2001). Effect of combination drying on the physico-chemical characteristics of carrot and pumpkin. J. Food Process. Preserv., 25(6), 447-460. https://doi.org/10.1111/j.1745-4549.2001.tb00472.x

Pinheiro Sant'Ana, H. M., Stringheta, P. C., Cardoso Brandão, S. C., Cordeiro de Azeredo, R. M. (1998). Carotenoid retention and vitamin A value in carrot (Daucus carota L.) prepared by food service. Food Chem., 61(1/2), 145-151. https://doi.org/10.1016/S0308-8146 (97)00084-8

Schwarz, M., Wray, V., Winterhalter, P. (2004). Isolation and identification of novel pranoanthocyanins from black carrot (Daucus carota L.) juice. J. Agric. Food Chem., 52, 5095-5101. https://doi.org/10.1021/jf0495791

Singleton, V. L., Rossi, J. A. (1965). Colorimetry of total phenolics with phosphomolybdic-phosphotungstic acid reagents. Am. J. Enol. Vitic., 16, 144-158.

Smeriglio, A., Denaro, M., Barreca, D., D’Angelo, V., Germanò, M. P., Trombetta, D. (2018). Polyphenolic profile and biological activities of black carrot crude extract (Daucus carota L. ssp. sativus var. atrorubens Alef.). Fitoterapia, 124, 49-57. https://doi.org/10.1016/j.fitote. 2017.10.006

Tang, Y. C., Chen, B. H. (2000). Pigment change of freeze-dried carotenoid powder during storage. Food Chem., 69, 11-17. https://doi.org/10.1016/S0308-8146(99)00216-2

Tseng, A., Zhao, Y. (2012). Effect of different drying methods and storage time on the retention of bioactive compounds and antibacterial activity of wine grape pomace (Pinot Noir and Merlot). J. Food Sci., 77(9), H192-H201. https://doi.org/10.1111/j.1750-3841.2012.02840.x

Van den Berg, H., Faulks, R., Fernando Granado, H., Hirschberg, J., Olmedilla, B., Sandmann, G., ..., Stahl, W. (2000). The potential for the improvement of carotenoid levels in foods and the likely systemic effects. J. Sci. Food Agric., 80, 880-912. https://doi.org/10.1002/ (SICI)1097-0010(20000515)80:7<880::AID-JSFA646> 3.0.CO;2-1

Yen, Y.-H., Shih, C.-H., Chang, C.-H. (2008). Effect of adding ascorbic acid and glucose on the antioxidative properties during storage of dried carrot. Food Chem., 107, 265272. https://doi.org/10.1016/j.foodchem.2007.08.013 